\title{
Effect of Iodine Treatment on Carbonization of Coal Tar Pitch
}

\author{
Eiichi Yasuda, Hisashi Kajiura* and Yasuhiro Tanabe
}

(Recieved July 25, 1995)

Research Laboratory of Engineering Materials

Tokyo Institute of Technology

4259 Nagatsuta, Midori-ku, Yokohama 226, Japan

${ }^{*}$ Research Fellow of the Japan Society for the Promotion of Science

The effect of iodine treatment on carbonization of coal tar pitch was investigated. Coal tar pitch with softening point of $101{ }^{\circ} \mathrm{C}$ was used as a starting material. The pitch specimen, molded into $6 \mathrm{~mm}$ in diameter and $20 \mathrm{~mm}$ in length, and iodine powder of about twice of the specimen weight were put into a test tube. After sealing the tube, they were heated at $90^{\circ} \mathrm{C}$ for iodine treatment. The specimens were preoxidized at $170{ }^{\circ} \mathrm{C}$ for 3 hours in air flow to stabilize the pitch. Then preoxidized specimens were heated for carbonization at a rate of $2.5^{\circ} \mathrm{C}$ /min up to $800{ }^{\circ} \mathrm{C}$ in Ar flow. The duration at the highest temperature was 1 hour. From the result of solvent fractionation using benzene and pyridine, iodine treatment and preoxidation treatment was known to increase molecular weight of components in the pitch. Carbon yield of the specimen was increased from $56 \%$ to $76 \%$ by iodine treatment for 20 hours. Microstructure of the carbonized specimens changed from flow type texture to mosaic one with increasing period of the iodine treatment.

KEYWORDS : Coal tar pitch, Iodine treatment, Carbon yield, Microstructure

\section{Introduction}

Carbon/carbon composites (C/C composites) are expected to be used at the critical environments where other materials cannot be served. Pitch is widely used as the matrix precursor of $\mathrm{C} / \mathrm{C}$ composites. In the production process of $\mathrm{C} / \mathrm{C}$ composites, however, impregnation and carbonization processes are applied repeatedly to attain useful density. Because the carbon yield of pitch is limited. In addition, it is difficult to keep their shape during carbonization as pitch melts at temperature range from 300 to $500{ }^{\circ} \mathrm{C}$.

Some researchers are trying to change properties of pitch by oxidation treatment termed preoxidation treatment, mild oxidation or air blowing oxidation ${ }^{1)}{ }^{3)}$. J.B.Barr et al. ${ }^{1)}$ reported that air blowing oxidation made pitch's softening point higher and dehydrogenative polymerization brought about between pitch components supported by oxygen. J.L.White et al. ${ }^{2)}$ carried out the oxidation process to stabilize pitch matrix in $\mathrm{C} / \mathrm{C}$ composites. They indicated that the oxidation process was an effective process to maintain the specimen's shape during carbonization.

Some papers pointed out that iodine doping is an effective method of coal or pitch characterization ${ }^{4)}-6$ ). Because iodine forms charge transfer complexes with components in pitch and creates radicals whose concentration reflects the structure of components in the pitch. However, the effect of iodine treatment on carbonization of pitch is not studied as long as we surveyed. The authors inserted an iodine treatment before preoxidation treatment. It was expected that iodine promotes polymerization reaction in the pitch components because iodine acts as an oxidizing agent. The purpose of this paper is to investigate the effect of iodine treatment on the carbonization behavior of coal tar pitch. 


\section{Experimental Procedure}

The coal tar pitch used in this study was supplied by Nippon Steel Chemical Corporation. Characteristics of the pitch were shown in Table 1. Iodine treatment was carried out at $90^{\circ} \mathrm{C}$ to prevent specimen's melting during the treatment. The pitch was fused and molded into $6 \mathrm{~mm}$ in diameter and $20 \mathrm{~mm}$ in length using a glass tube. The pitch specimen and iodine powder of which weight was about twice of the specimen were put into a test tube separated each other by carbon felt. Then the test tube was put into dry oven heated at $90{ }^{\circ} \mathrm{C}$ and kept for 1-20 hours. Preoxidation treatment for stabilization of pitch was carried out in an electric furnace to the specimen treated with iodine at $170{ }^{\circ} \mathrm{C}$ for 3 hours in air flow. As exhaust gas seemed to include gas phase iodine, it passed through xylene to remove iodine gas. The specimen after preoxidation treatment was heated for carbonization at a rate of $2.5^{\circ} \mathrm{C}$ /min up to $800{ }^{\circ} \mathrm{C}$ in Ar flow. The duration at the highest temperature was 1 hour. The residual weight was divided by the weight before the iodine treatment to estimate carbon yield. The microstructure of the carbonized specimens was examined by observing their polished section under polarized light microscope. Solvent fractionation by benzene and pyridine was carried out to make clear the change of components in pitch by iodine treatment and preoxidation treatment. Five grams of specimen was crashed into pieces with an agate mortar and was put into $250 \mathrm{ml}$ of solvent. The solution was stirred for 24 hours at room temperature, followed by filtration.

\section{Results and Discussion}

Fig.1 shows weight change of the specimens after the iodine treatment and that after the preoxidation treatment, and the carbon yield after heat treatment

Table 1 Characteristics of pitch used.

\begin{tabular}{ll}
\hline Softening Point & $101^{\circ} \mathrm{C}$ \\
Fixed Carbon & $53.3 \%$ \\
Toluene Insoluble & $14.6 \%$ \\
Quinoline Insoluble & $0.59 \%$ \\
Ash & $0.02 \%$ \\
Sulfur & $0.50 \%$ \\
\hline
\end{tabular}

at $800{ }^{\circ} \mathrm{C}$ as a function of iodine treatment period. During iodine treatment, specimen's weight increased in roughly proportional to the period of iodine treatment, and about $38 \%$ of weight gain was obtained after iodine treatment for 20 hours. The weight after preoxidation treatment decreased. However, about one third of introduced iodine remained after the treatment. From EPMA (electron probe X-ray microanalyzer) analysis, it was observed that iodine was introduced from the surface to the inside and penetrated around $1.0 \mathrm{~mm}$ in depth after iodine treatment for 20 hours. After preoxidation treatment, some pores were observed in the area where iodine was introduced. These pores were not observed after iodine treatment, that is, at the stage before preoxidation. This result considered to suggest that some reactions between iodine and components in the pitch occurred during preoxidation treatment to produce gas species. As shown in Fig.1, carbon yield of the specimen was increased from $56 \%$ to $76 \%$ by iodine treatment for 20 hours. In the carbonized specimen, iodine was not detected with EPMA analysis. It was found that iodine is an effective agent to improve carbon yield of the pitch.

Photo 1 shows optical micrographs of the carbonized specimen. For the non-treated specimen (a), flow type texture could be observed. On the other hand, mosaic texture could be observed for the specimens treated with iodine for 10-hour (b) and 20-hour (c). This

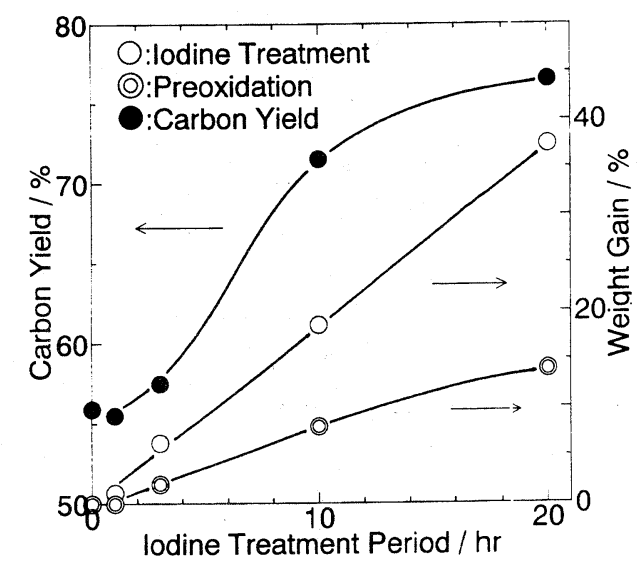

Fig.1 Weight change of specimens after the iodine treatment and that after preoxidation treatment, and the carbon yield after heat treatment at $800{ }^{\circ} \mathrm{C}$ as a function of the iodine treatment period. 


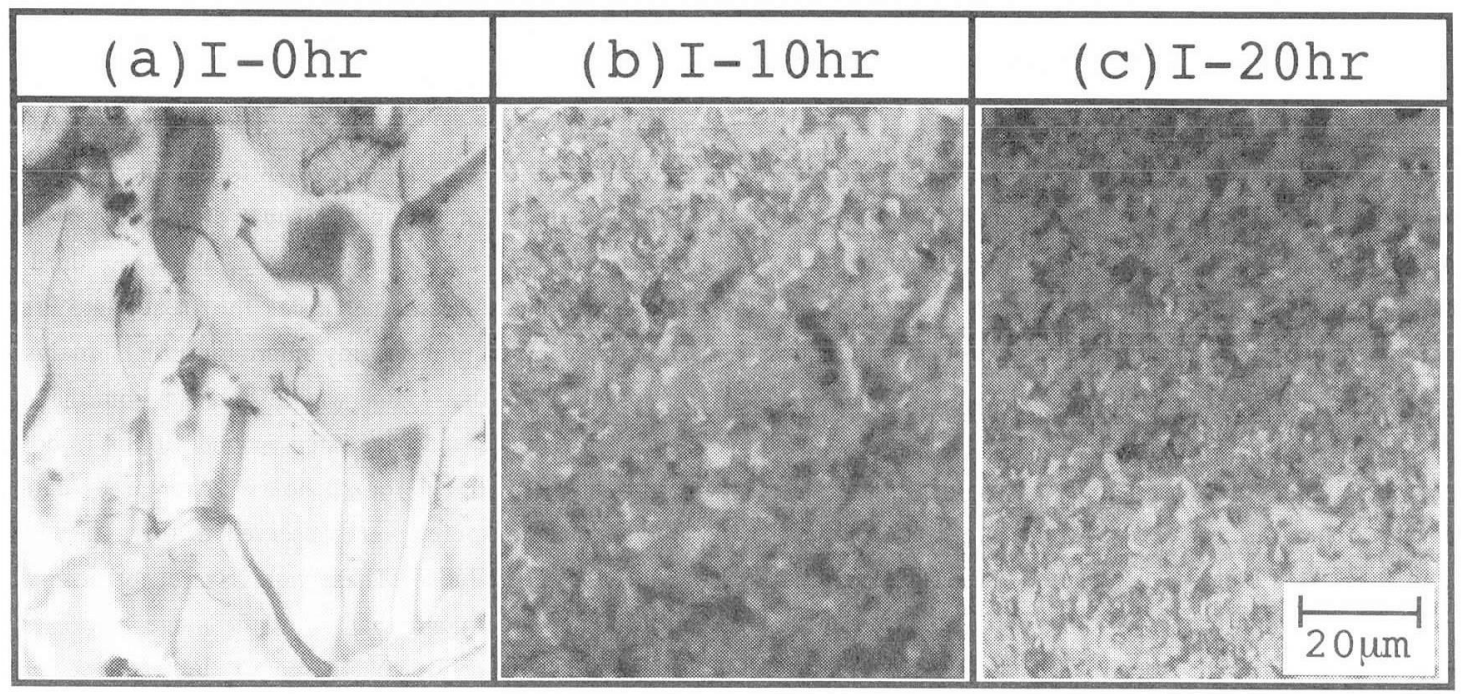

Photo.1 Optical micrographs of the carbonized specimen treated with iodine for

(a) $0 \mathrm{hr}$, (b) $10 \mathrm{hr}$, and (c) $20 \mathrm{hr}$.

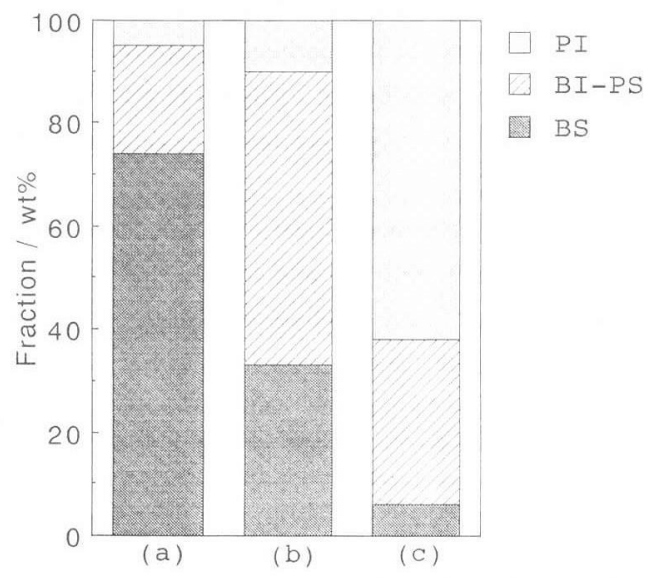

Fig.2 Results of solvent fractionation of (a) raw pitch, (b) I-20hr, and (c) I-20hr+preoxidation.

mosaic texture was mainly observed at the area where iodine seemed to be introduced. The microstructure was changed from flow type texture to mosaic one with the increase of the iodine treatment period, in other words, increasing of introduced iodine.

Fig. 2 indicates the results of solvent fractionation of (a) raw pitch, (b) after iodine treatment for 20 hours, and (c) after iodine treatment for 20 hours and preoxidation treatment. Here, BS, BI-PS, and PI indicate benzene soluble, benzene insoluble-pyridine soluble, and pyridine insoluble fraction, respectively. It was reported that molecular weight of fractions increased in order of BS, BI-PS and PI ${ }^{7}$. Molecular weight of PI fraction was reported to be more than $2000^{7}$. From these results, iodine treatment and preoxidation treatment were known to increase the molecular weight of components in the pitch. It seemed that some of iodine went away from specimen with hydrogen, which promoted dehydrogenative polymerization in pitch. The change of molecular weight occurred during iodine treatment and preoxidation treatment is concidered to be one of the main reasons for increasing carbon yield and changing microstructure from flow type texture to mosaic one.

\section{Conclusion}

The effect of iodine treatment on carbonization of coal tar pitch was investigated and the following was concluded.

(1) Carbon yield of the pitch was increased from $56 \%$ to $76 \%$ by iodine treatment for 20 hours. It was found that iodine was an effective agent to improve carbon yield of the pitch.

(2) Optical microstructure of carbonized specimen was changed from flow type texture to mosaic one with the increase of iodine treatment period. 


\section{Acknowledgment}

One of the authors, H.Kajiura, is indebted to the Ministry of Education, Science and Culture of Japan for financial support by Grant-in-Aid for JSPS Fellows No.2339.

\section{References}

1) J.B.Barr and I.C.Lewis, Carbon 16 (1978) 439-444.

2) J.L.White and P.M.Sheaffer, Carbon 27 (1989) 697707.
3) J.Drbohlav and T.K.Stevenson, Carbon 33 (1995) 693-711.

4) T.Yokono, T.Imamura and Y.Sanada, Sekiyu Gakkaishi 30 (1987) 59-62.

5) H.de Lopez, T.Yokono, K.Murakami, Y.Sanada and H.Marsh, Fuel 66 (1987) 866-867.

6) M.Sakaki and Y.Sanada, Sekiyu Gakkaishi 34 (1991) 218-235.

7) M.Inagaki, Tanso zairyou kougaku (1985) p.20-21, THE NIKKAN KOGYO SHIMBUN, LTD. 